\title{
Gorlin Goltz Syndrome - Familial Inheritance - A Rare Case Series
} Dr. Ravinder Singh Bedi ${ }^{1}$, Dr. Jitender Kumar Aurora ${ }^{2}$, Dr. Himanshu Chauhan ${ }^{3}$, Dr. M Sharique Sayeed ${ }^{4 *}$

\footnotetext{
${ }^{1}$ Professor and Head Department of Oral and Maxillofacial Surgery, Saraswati Dental College and Hospital, Lucknow, Uttar Pradesh, India

${ }^{2}$ Professor Departments of Oral and Maxillofacial Surgery Saraswati Dental College and Hospital, Lucknow, Uttar Pradesh, India

${ }^{3}$ Senior Lecturer Department of Oral and Maxillofacial Surgery Saraswati Dental College and Hospital, Lucknow, Uttar Pradesh, India

${ }^{4}$ Final year postgraduate student, Department of Oral and Maxillofacial Surgery Saraswati Dental College and Hospital, Lucknow, Uttar Pradesh, India
}

DOI: $10.36347 /$ sids.2020.v07i09.001

| Received: 01.10.2019 | Accepted: 10.10.2019| Published: 09.09.2020

*Corresponding author: Dr. M Sharique Sayeed

Abstract

Gorlin- Goltz syndrome (GGS) is a rare, autosomal dominant syndrome caused by mutations of the patched gene (PTCH) on chromosome 9q (22.3-q31). It has a high level of penetrance and diverse expression, commonly associated with basal cell carcinomas, odontogenic keratocysts, palmar and/or plantar pits and falx cerebri calcifications. Two major findings or one major finding and two minor findings confirm the diagnosis. More than 100 minor criteria are mentioned in the literature for diagnosing GGS [1]. Despite diverse manifestations this syndrome is under reported, three cases of familial inheritance are reported in India till date. Early diagnosis and genetic counseling are essential for managing the syndrome. Total of 65 variants of PTCH mutations have been documented in literature [2], thus it would be not unanticipated for affected patients and their family members to have a spectrum of different genetic and clinical anomalies. There are only 64 cases reported till date since 1977 from India out of which this is the fourth case report showing the hereditary involvement. All the three previously reported cases had only two affected members but this is the first case series reporting three affected of GGS with familial inheritance (mother and both her children). Their diverse manifestation in each are reported here which alerts the clinician and gives an insight for prompt diagnosis and its early management.

Keywords: Gorlin- Goltz Syndrome, Odontogenic Keratocyst, Major Criteria, Minor Criteria.

Copyright @ 2020: This is an open-access article distributed under the terms of the Creative Commons Attribution license which permits unrestricted use, distribution, and reproduction in any medium for non-commercial use (NonCommercial, or CC-BY-NC) provided the original author and source are credited.

\section{INTRODUCTION}

Gorlin Goltz Syndrome (GGS) is an autosomal dominant disorder having prodigious penetrance. The syndrome exhibits inconsistent manifestations, caused by mutations in patched tumor suppressor gene (PTCH) [1]. Due to its inherent nature of unpredictable expressivity not all findings are present in each patient. The incidence of this syndrome is estimated to be 1 in 50,000 to 150,000 in general population but professed the may vary according to the geographical regions and is acknowledged to run in families with equal preference to both genders [2]. GGS is same as Nevoid Basal Cell Carcinoma (NBCC), jaw cyst bifid rib basal cell nevus syndrome and nevoid basalioma. The diagnosis is proven by the existence of two major criteria or one major criterion and two minor criteria. More than a hundred minor criteria have been described in the literature for establishing Gorlin-Goltz syndrome. The principal findings include the occurrence of Odontogenic Keratocyst (OKC), basal cell carcinoma, palmar or plantar pits and bilamellar calcifications of the falx cerebri [3]. It was first reported in 1894 by
Jarisch and White. Robert J. Gorlin and Robert W. Goltz described the diverse syndrome, consisting of the presence of multiple nevoid basal cell epitheliomas, jaw cysts and bifid ribs [4]. Despite manifold manifestations this syndrome is under-reported and only a handful of cases with familial inheritance have been reported to date. Early diagnosis, treatment as well as genetic counseling are essential for this syndrome. A case of Gorlin Goltz syndrome with familial inheritance (mother and both her children) and their assorted manifestations in each are reported here. This case report entices the valuable role of a clinician in early diagnosis and prompt management of this syndrome.

\section{Case Report: Patient 1 (Mother)}

- A 30 years old female patient visited the Department of Oral and Maxillofacial Surgery, with a chief complaint of pain and swelling on the left side of the lower jaw for 6 months which was slowly progressive. The patient did not affirm any other associated symptoms. Her medical, family, dental and personal histories were noncontributory. 
- There was a diffuse swelling in the left lower third of the face with no secondary changes noted over it. On palpation, there was no local rise in temperature; the swelling was not tender, bony hard in consistency causing vestibular obliteration in the region of 36 and 37 extending distally up to the ascending border of the ramus with no history of paresthesia.

- Intraorally, all permanent teeth were present except the third molars in all four quadrants which were clinically missing. Aspiration yielded thick dirty white cheesy fluid. The patient was then subjected to further radiographic examination.

- Orthopantomogram (Figure 1) revealed impacted 18, 28, 48, missing 38 and multiple unilocular well-defined radiolucencies with sclerotic borders located in posterior maxilla and mandible bilaterally. CT scan revealed that the lesion has not perforated the buccal and lingual cortical plates of the mandibular ramus and angle region bilaterally.

- The presence of multiple cysts in the jaws, associated with unerupted teeth, raised suspicion of Gorlin Goltz Syndrome and other relevant investigations were done along with a thorough physical examination to look out for other signs.

- Clinical examination revealed multiple palmer and planter pits (Figure 2), macrocephaly (occipitofrontal circumference $61 \mathrm{~cm}$, Figure 3 ), anteroposterior view radiograph of chest and ultrasonography of the abdomen did not reveal any anomaly. CT scan displayed bifid spine (Figure 4). The patient was then evaluated systemically for other anomalies of the skeletal, cardiovascular or central nervous system, which did not reveal any specific abnormalities.

- Incisional biopsies of the swelling on the left side of mandible and both the sites on the maxilla were done. Histopathological examination was suggestive of odontogenic keratocyst with parakeratinized stratified squamous epithelium.

- Since two major criteria's (multiple odontogenic keratocyst and multiple palmar pits) and two minor criteria's (macrocephaly and bifid spine) were met hence a final diagnosis of Gorlin Goltz syndrome was made. The patient was treated surgically; enucleation of all cysts and peripheral osteotomy was done along with application of Carnoy's solution. The patient is being followed up regularly.

- As Gorlin-Goltz syndrome is an autosomal dominant with high penetrance trait both the children ( 2 daughters) of the patient were then screened and a full clinical and radiological evaluation was carried out.
Case Report: Patient 2 (Elder Daughter-9 Years)

On general physical examination multiple palmers pits (Figure 5), macrocephaly (occipitofrontal circumference $60 \mathrm{~cm}$, Figure 6) and frontal bossing (Figure 7) were observed along with syndactyly and polydactyly of the left foot digits (Figures 8 and 9). Orthopantomogram revealed multiple radiolucencies in the mandible (Figure 10). CT scan suggested that the lesion has perforated the buccal and lingual cortical plate of the mandibular ramus and angle region.

Incisional biopsy of the mandibular left ramus region was done which was diagnosed as odontogenic keratocyst with similar histopathological features as that of the mother. Further systemic evaluation did not reveal any other anomaly.

Three major criteria (OKC proved histologically, multiple palmer pits and a positive family history of Gorlin Goltz syndrome i.e. her mother) and four minor criteria (macrocephaly, frontal bossing, syndactyly, and polydactyly of the left feet digits) fulfill the major and minor criteria hence confirmed the diagnosis of Gorlin Goltz syndrome.

\section{Case Report (Younger Daughter-4 Years)}

On general physical examination, multiple palmer pits (Figure 11) macrocephaly (occipitofrontal circumference $56 \mathrm{~cm}$, Figure 12) with a history of glaucoma (treated). Orthopantomograph revealed a unilocular well-defined radiolucency associated with a developing 43 extending from the base of the mandible to the apices of 83 and 84 (Figure 13). The systemic evaluation did not reveal any other anomaly.

The findings were concordant to that of Gorlin Goltz syndrome. Major criteria being histologically proven odontogenic keratocyst, multiple palmer pits and first degree relatives already have the syndrome (i.e. mother and elder sister). Whereas the minor criteria being macrocephaly and glaucoma.

\section{DISCUSSION}

Gorlin Goltz syndrome is indigenous in presentation customarily reported in white, mostly through the first to third decade of life with equal tendencies in both genders [5]. PTCH gene on chromosome $9 q(22.3-q 31)$ is the persuasive gene which is a human homolog of the Drosophila segment polarity gene [6]. This disorder is autosomal dominant in nature but can arise intrinsically with or without any phenotypic dissemination [7]. Almost $60 \%$ of patients have no known affected family members and $35-50 \%$ of these represent new mutations $[8,9]$.

The variable phenotypic expression reflects variations in penetrance, the expression of different mutations within the same gene and/or the effects of modifier genes and environmental factors. A total of 65 variants of PTCH mutations have been documented in 
literature $[10,11]$, thus it would be not unanticipated for affected patients and their family members to have a spectrum of different genetic and clinical anomalies just as reported in our cases.

The predominance of GGS is assessed as 1 in 50,000 to 150,000 in the general population [12,13], however Evans et al. reported the prevalence as 1in 560,000 in United Kingdom [14] and Farndon et al. reported the prevalence as 1 in 57,000 [15]. In Australia Shanley et al. reported the prevalence as 1 in 64,000 and in Italy Lo Muzio et al. estimated the prevalence as 1 in 256,000 [16,17].

There are only 64 cases reported to date since 1977 from India out of which this is the fourth case report showing the hereditary involvement. All three previously reported cases had only two affected members but this is the first case series reporting three affected family members $[12,18,19]$.

Woolgar et al. in 1987 concluded that the mean age group for syndromic cases is 10 to 30 years and females are more affected than males whereas in the Indian scenario the mean age reported is 23.8 years with a male to female ratio of 1:0.7 [20,21].

Extensive variation in the occurrence of odontogenic keratocysts in GGS patients ranging from $62 \%$ to $100 \%$ has been reported in the literature [22]. This association was found in $100 \%$ of our case series as all the 3 patients had odontogenic keratocysts. In syndromic cases, maxillary molar areas are more frequently affected with a recurrence rate of nearly $63 \%$ [20].

Nearly $35 \%-87 \%$ of the syndromic patient's exhibit palmarplanter pits, which is $80 \%$ patients, develop by the age of 15 years and by the age of 20 nearly $85 \%$ patients exhibit these pits occurring most commonly on the palms than on the soles. These pits arise due to partial or complete absence of dens keratin in sharply defined areas [13]. Palmar pits were found in all the three patients in our cases. Ectopic calcification of falx cerebri was not found in any of the three patients discussed in this case series, despite being reported to have been found in $21.2 \%$ to $92 \%$ patients worldwide [21].

Macrocephaly with an increased occipitofrontal circumference i.e. greater than $55 \mathrm{~cm}$ was found in all the three patients. Relative macrocephaly (occipitofrontal circumference $>55 \mathrm{~cm}$ in adults) has been reported in $5 \%-80 \%$ of the cases whereas hypertelorism is reported to be found in $6 \%$ $78 \%$ patient [17] which was evident in only the elder daughter.

Fibroma and ovarian cysts in syndromic females is a finding in $25 \%-50 \%$ of affected patients with GGS and frequently present bilaterally in almost $75 \%$ cases [23]. Bifid, fused, wide, partially missing, or underdeveloped ribs are typical findings in 16\%-58\% of GGS patients [24, 25]. None of these were consistent with our finding, excluding spina bifida which was seen in the mother.

Of the 3 previously reported cases with familial inheritance in India [12,18,19] odontogenic keratocyst was found in all the cases except in one patient as reported by Nikam B et al. [19] where a 28 years male presented with multiple palmer pits, kyphoscoliosis, Sprengel deformity but his 70-year-old father diagnosed with Gorlin Goltz syndrome had multiple OKCs which was a common finding in all the family members in our case report.

Falx cerebri and tentorium cerebri calcification were reported by Chakraborty P et al. [18] in a 32-yearold mother and her 12 years old son. Bifid ribs was reported by Hegde S, Shetty SR [12] in a 39 years old father but were not found in her 8-year-old daughter. Calcification of the cerebri and bifid ribs was not seen in any of the three patients in our case.

Evans et al. in 1993 enlisted the diagnostic benchmarks for GGS which was subsequently improved by Kimonis et al. in 1997 stating that the diagnosis of GGS can be established when two major, or one major and two minor criteria are present as enlisted below in Table 1 [11,13]. Further Lo Muzio et al. in 1999 and Manfredi M et al. in 2004 mentioned various other diagnostic findings of GGS enlisted in Table $2[3,17]$.

\section{CONCLUSION}

The inception of Basal Cell Carcinoma (NBCC) or a histologically confirmed odontogenic keratocyst in a patient below the age of 20 years must alert the clinician to explore other diagnostic features, to look for the likelihood of the patient suffering from Gorlin Goltz syndrome. A thorough Intra and extraoral inspection and assessment must be done along with appropriate radiographic investigations.

Various authors have recommended the need for neurological examination every 6 months, panoramic radiograph, dermatological and systemic examination once a year, from the age of 7 years, in patients whose first-degree relatives are already diagnosed with the syndrome. This would benefit to detect anomalies in suspected individuals in its initial stages so that prompt management of the detected anomalies is initiated reducing the extent of damage. Prenatal ultrasound to detect CNS and skeletal abnormalities in syndromic mothers along with genetic analysis is recommended to identify carriers.

Early diagnosis, genetic counseling, and treatment are imperative to prevent long term sequelae including malignancy and oromaxillofacial deformation and destruction. 


\section{Ethical Approval}

The authors certify that they have obtained all appropriate patient consent forms. In the form, the patients have given their consent for their images and other clinical information to be reported in the journal. The patients understand that their names and initials will not be published and due efforts will be made to conceal their identity, but anonymity cannot be guaranteed.

\section{Conflicts of Interest}

There are no conflicts of interest.

\section{ACKNOWLEDGMENT}

We would like to thank Dr. Charu and Dr. Adrineel, residents for their valuable assistance during documentation workup and record maintenance of the subjects.

Table-1: Diagnostic criteria for GGS [3, 7]

\section{MAJOR CRITERIA}

More than two basal cell carcinoma or one basal cell carcinoma under the age of twenty years of age or more than ten basal cell nevi.

Any odontogenic keratocyst (proven on histology) or polyostotic bone cyst.

Three or more cutaneous palmar or plantar pits.

Bilamellar calcification of the falx cerebri.

Bifid, fused or markedly splayed ribs.

First degree relatives with nevoid basal cell carcinoma.

\section{MINOR CRITERIA}

Macrocephaly determined after adjustment for height.

Congenital malformations: cleft lip or palate, frontal bossing, "coarse face," moderate or severe hypertelorism.

Other skeletal abnormalities: Sprengel deformity, marked pectus deformity, marked polydactyly or syndactyly of the digits.

Radiological abnormalities: Bridging of the sella tursica, vertebral anomalies such as hemivertebrae, fusion or elongation of the vertebral bodies, modeling defects or flame shaped lucencies of the hands or feet.

Ovarian fibroma.

Medulloblastoma, eye anomaly (cataract, coloboma, microphthalmus and glaucoma).

Table-2: Other diagnostic findings in GGS [3, 9]

\section{A. SKELETAL ANAOMALIES}

1. Bifid ribs, splayed/ fused ribs, absent/ rudimentary ribs - may be bilateral

2. Scoliosis

3. Hemivertebrae

\section{B. CRANIOFACIAL ANOMALIES}

1. Frontal bossing (occipitofrontal circumference 60 cms. or $>$ in adults)

2. Brachycephaly

3. Macrocephaly

4. Coarse face

5. Calcification of the falxes

6. Tentorium cerebelli calcification

7. Bridged sella tursica

\section{NEUROLOGICAL ANOMALIES}

1. Agenesis / disgenesis of corpus callosum

2. Congenital hydrocephalus

3. Mental retardation

\section{OROPHARYNGEAL ANOMALIES}

1. Odontogenic Keratocysts - (Single or multiple, 3 3. Cleft lip/ palate unilocular/ multilocular cysts)

2. High arched palate or prominent ridges

4. Flame - Shaped lucencies of hand/ feet

5. Polydactyly

6. Syndactyly or both

7. Shortened 4 th metacarpal

8. Heavy fused eyebrows

9. Broadened nasal root

10. Low positioning of occiput

11. Congenital blindness due to corneal opacity

12. Congenital or precocious cataract or glaucoma

13. Coloboma of iris, choroids or optic nerve

14. Convergent or divergent strabismus and nystagmus

4. Medulloblastoma (developing in the first two years of life) 5. Meningioma

4. Malocclusions or dental ectopic position

5. Impacted teeth and / or agenesis

\section{Basal cell carcinoma \\ 2. Palmar and or plantar pits}

\section{F. ANOMALIES OF THE REPRODUCTIVE SYSTEM}

\begin{tabular}{l|l} 
1. Uterine and ovarian fibromas & 3. Supernumerary nipple
\end{tabular}

2. Calcified ovarian cysts

4. Hypogonadism and cryptorchidism

\section{G. CARDIAC ANOMALIES}

1. Cardiac fibromas 


\section{REFERENCES}

1. Cohen MM. Nevoid Basal Cell Carcinoma-A molecular biology and new hypothesis. Int $\mathbf{J}$ Oral Maxillofac Surg. 1996;27:216-3.

2. Kumar S, Eshanth R, Indiran V, Mariappan K, Maduraimuthu P. A rare association of GorlinGoltz syndrome. Neurology India. 2018 May $1 ; 66(3)$.

3. Manfredi M, Vescovi P, Bonanini M, Porter S. Nevoid basal cell carcinoma syndrome: a review of the literature. International journal of oral and maxillofacial surgery. 2004 Mar 1;33(2):117-24.

4. Jarisch W. Zur Lehre von den Hautgeschwülsten. Archives of Dermatological Research. 1894; 28: 162-222.

5. Gorlin RJ, Goltz RW. Multiple nevoid basal-cell epithelioma, jaw cysts and bifid rib syndrome. The New England Journal of Medicine. 1960; 262: 908912.

6. Hain H, Wicking C, Zaphiropolous PG, Gailanin MR, Shanley S. Mutations of the human homolog of Drosophila patched in the nevoid basal cell carcinoma syndrome. Cell. 1996; 85: 841-851.

7. Gorlin RJ, Yunis JJ, Tuna N. Multiple nevoid basal- cell carcinoma, odontogenic keratocysts and skeletal anomalies syndrome. Acta Dermatology and Venereology. 1963; 43: 39-55.

8. Gorlin RJ, Sedaño HO. The multiple nevoid basal cell carcinoma syndrome revisited. Birth Defects. 1971; 7: 140-148.

9. Gorlin RJ. Nevoid basal cell carcinoma syndrome. Genetics in Medicine. 1987; 66: 98-113.

10. Gorlin RJ. Nevoid basal cell carcinoma syndrome. Dermatologic Clinics. 1995; 13: 113-125.

11. Evans DG, Ladusans EJ, Rimmer S, Burnell LD, Thakker N. Complications of the naevoid basal cell carcinoma syndrome: results of a population-based study. Journal of Medical Genetics.1993; 30: 460464.

12. Hegde S, Shetty SR. Radiological features of familial Gorlingoltz syndrome. Imaging Science in Dentistry. 2012; 42: 55-60.

13. Kimonis VE, Goldstein AM, Pastakia B, Yang ML, Kase R. Clinical manifestations in 105 persons with nevoid basal cell carcinoma syndrome. American Journal of Medical Genetics. 1997; 69: 299-308.

14. Evans DG, Sims DG, Donnai R. Family implications of neonatal Gorlin's syndrome.
Archives of Disease in Childhood. 1991; 66: 1162 1163.

15. Farndon PA, Del Mastro RG, Evans DG, Kilpatrick MW. Location of gene for Gorlin syndrome. Lancet. 1992; 339: 581-582.

16. Shanley S, Ratcliffe J, Hockey A, Haan E, Oley C. Nevoid basal cell carcinoma syndrome: review of 118 affected individuals. American Journal of Medical Genetics. 1994; 50: 282-290.

17. Lo Muzio L, Nocini PF, Savoia A, Consolo U, Procaccini M. Nevoid basal cell carcinoma syndrome. Clinical findings in 37 Italian affected individuals. Clinical Genetics.1999; 55: 34-40.

18. Chakraborty P, Singh AP, Joshi P, Pradhan S, Kumari R. Gorlin goltz syndrome: a clinicoradiologic insight. International Journal of Contemporary Medical Research. 2016; 3: 19091911.

19. Nikam B, Kshirsagar A, Shivhare P, Garg A. Familial multiple basal cell carcinoma (Gorlin's syndrome): A case report of a father and son. Indian Journal of Dermatology. 2013; 58: 481-484.

20. Woolgar JA, Rippen JW, Browne RM. The odontogenic keratocyst and its occurrence in the nevoid basal cell carcinoma syndrome. Oral Surgery, Oral Medicine, Oral Pathology. 1987; 64:727-730.

21. Muzio LL, Nocini P, Bucci P, Pannone G, Procaccini M. Early diagnosis of nevoid basal cell carcinoma syndrome. Journal of the American Dental Association. 1999; 130: 669-674.

22. Lata J, Verma N, Kaur A. Gorlin-Goltz syndrome: A case series of 5 patients in North Indian population with comparative analysis of literature. Contemporary Clinical Dentistry. 2015; 6: 192 201.

23. Habibi A, Jafarzadeh H. Nevoid basal cell carcinoma syndrome: A 17-year study of 19 cases in Iranian population (1991-2008). Journal of Oral Pathology and Medicine. 2010; 39: 677-680.

24. Rai S, Gauba K. Jaw cyst-Basal cell nevus-Bifid rib syndrome: a case report. Journal of Indian Society of Pedodontics and Preventive Dentistry. 2007; 25: 137-139.

25. Patil K, Mahima VG, Gupta B. Gorlin syndrome: A case report. Journal of Indian Society of Pedodontics and Preventive Dentistry. 2005; 23: 198-203. 